\title{
Revista \\ Brasileira \\ de Enfermagem \\ REBEn \\ Avaliação qualitativa da relação de atores sociais com a loucura em um serviço substitutivo de saúde mental
}

PESQUISA

\author{
Qualitative assessment of the relationship of social actors with madness \\ in a substitutive mental health service \\ Evaluación cualitativa de la relación de actores sociales con la locura en \\ un servicio sustitutivo de salud mental
}

\author{
Fernanda Barreto Mielke', Agnes Olschowsky", Leandro Barbosa de Pinho", \\ Christine Wetzel", Luciane Prado Kantorski"I \\ ' Universidade Federal do Rio Grande do Sul, \\ Programa de Pós-Graduação em Enfermagem (Doutoranda). Porto Alegre-RS, Brasil. \\ "Universidade Federal do Rio Grande do Sul, Escola de Enfermagem, \\ Programa de Pós-Graduação em Enfermagem. Porto Alegre-RS, Brasil. \\ III Universidade Federal de Pelotas, Faculdade de Enfermagem, \\ Programa de Pós-Graduação em Enfermagem. Pelotas-RS, Brasil.
}

Submissão: 01-03-2011 Aprovação: 29-07-2012

\section{RESUMO}

Este estudo tem por objetivo avaliar qualitativamente a relação de atores sociais com a loucura a partir das experiências produzidas em um Centro de Atenção Psicossocial no contexto brasileiro. Trata-se de um recorte de um estudo de avaliação qualitativa realizado em um Centro de Atenção Psicossocial do Sul do Brasil. Baseou-se na utilização do referencial teóricofilosófico da Avaliação de Quarta Geração. Como dispositivo metodológico, aplicou-se uma versão adaptada do Círculo Hermenêutico-Dialético. Os depoimentos perseguem a desinstitucionalização como paradigma da atenção em saúde mental, evidenciando a necessidade de combater os vícios carregados de condutas cristalizadas e excludentes, típicas do modelo manicomial. No entanto, ainda é possível visualizar na prática uma mescla de modelos, responsáveis por práticas ampliadas e inovadoras, além de outras cristalizadas e excludentes. Esperamos que ele possa problematizar o cotidiano dos mesmos, abrindo caminhos para compreender melhor a loucura, o louco e suas relações.

Descritores: Saúde Mental; Enfermagem Psiquiátrica; Reforma dos Serviços de Saúde.

\section{ABSTRACT}

This study aims to evaluate qualitatively the relationship between social actors and the madness. It was based in experiences produced in a Psychosocial Care Center in the Southern Brazilian context. This is a clipping from an evaluative and qualitative study. Was utilized the Fourth Generation Evaluation as a theoretical-philosophical framework. The methodological device applied was a adapted version of the Hermeneutic-dialectic circle. The statements haunt deinstitutionalization as a paradigm of mental health care, highlighting the need to combat the vices born of crystallized and exclusionary conduct, the typical model asylum. However, we can still see in practice a mixture of models, responsible for enhanced and innovative practices, and other crystallized and exclusive. Hopefully he can discuss the daily life of them, opening the way for understanding best madness, crazy and their relationships.

Key words: Mental Health; Psychiatric Nursing; Health Services Reform.

\section{RESUMEN}

Este estudio pretende evaluar cualitativamente la relación de actores sociales con la locura, a partir de experiencias producidas en un Centro de Atención Psicosocial brasileño. Se trata de un recorte de un estudio de evaluación cualitativa realizado en un Centros de Atención Psicosocial del Sur de Brasil. Se basó en el referencial teórico-metodológico de la Evaluación de Cuarta Generación. Como dispositivo metodológico, se aplicó una versión adaptada del círculo hermenéutico-dialéctico. Los discursos persiguen la desinstitucionalización como paradigma de atención en salud mental, evidenciando la necesidad de combatir los vicios cargados de conductas cristalizadas y que excluyen, típicas del modelo manicomial. Todavía, aún es posible visualizar en la práctica una mescla de modelos, responsables por prácticas ampliadas e innovadoras, además de otras cristalizadas y excluyentes. Esperamos que pueda problematizar el cotidiano de los mismos, abriendo caminos para comprender mejor la locura, el loco y sus relaciones. Palabras clave: Salud Mental; Enfermería Psiquiátrica; Reforma de los Servicios de Salud. 


\section{INTRODUÇÃO}

Todos nós, seres humanos, somos fruto da relação que temos com o mundo que nos rodeia. É nele que agimos, falamos, nos posicionamos, compartilhamos, pensamos, interagimos.

A história da humanidade nos mostra esse movimento. Desde a Grécia antiga, por exemplo, o homem vem buscando explicações capazes de entender as transformações ocorridas no mundo por meio das relações do homem com a natureza. $\mathrm{E}$, isso se produz por aproximações, distanciamentos, conflitos, contradições que intensificam debates e nos desafiam com sujeito em movimento.

Foi assim nos diversos campos do conhecimento humano, entre eles, o campo da saúde. Com os avanços tecnológicos, foi possível combater epidemias históricas, produzir novas técnicas e entender como o organismo humano adoece, num movimento de "fora" para "dentro". No entanto, durante séculos, parte dessas mudanças foi se cristalizando em certas verdades absolutas, que reduziram aspectos do processo saúde/doença a explicações causais que reproduzem parcialmente as diferentes demandas necessárias à complexidade dessa compreensão.

Como exemplo, citamos a participação da medicina nesse processo. Mesmo diante do conhecimento científico acumulado desde o final dos anos de 1970, quando se iniciam os debates em torno da necessidade do redimensionamento do processo saúde/doença e da difusão desse conhecimento em vários estudos, ainda notamos forte influência de um conhecimento materialmente estruturado a partir do iluminismo francês. O período iluminista, derivado do conhecimento renascentista, veiculava a necessidade de "explorar" o corpo para livrá-lo da doença, tendo, para isso, que explicar os fatos, investigar as causalidades, a conformação anatômica do sujeito, o aparecimento ou a supressão de sinais/sintomas, o reaparecimento da condição de adoecimento, seja no contexto individual ou coletivo(1).

Esse contexto é resultado de um processo histórico de cultivo à racionalidade experimental do conhecimento humano, iniciado por pensadores como Francis Bacon e René Descartes. Descartes introduziu toda uma estrutura metodológica que ficou conhecida como o cogito cartesiano, fundando o método da dúvida, baseando-se na certeza de que, no pensamento e no ser que pensa, pode existir uma certeza - "penso, logo existo"(2).

O pensamento de Descartes proporcionou avanços importantes nas diversas áreas do conhecimento. Na medicina, possibilitou a consolidação de uma medicina clínico-positivista, responsável pela defesa da cisão do ser humano em parcelas e pela necessidade de estudo aprofundado de suas estruturas, para determinar as causas, os efeitos e as consequências dos agentes externos, que eram causadores de doenças. A passagem a seguir pode sintetizar o tamanho da sua influência teórico-filosófica na constituição moral e hegemônica da ciência médica, agora com caráter mecanicista, experimentalista e objetivado ${ }^{(3)}$ :

Da descrição dos corpos inanimados e das plantas, passei à dos animais e especificamente à dos homens [...] Porém, para que se possa ver de que modo eu lidava com esta matéria, quero mostrar aqui a explicação do movimento do coração e das artérias, o qual, sendo o primeiro e o mais geral que se observa nos animais, consentirá julgar com facilidade, a partir dele, o que se deve pensar de todos os outros. E, para que seja mais fácil entender o que vou dizer a esse respeito, desejaria que todos os que não são peritos em anatomia se dessem ao trabalho, antes de ler isto, de mandar cortar diante deles o coração de um grande animal que possua pulmões, já que é em tudo parecido com o do homem, e que peçam para ver as duas câmaras ou concavidades nele existentes

No campo da saúde mental, essa realidade não foi diferente, porque a evolução do conhecimento humano foi acompanhada, paralelamente, de explicações teóricas e práticas de intervenção no fenômeno da loucura. Passando pela doutrina hipocrático-galênica da Grécia antiga, até a doutrina demonista da Idade Média. E, foi com o médico Philippe Pinel, em seu Traité médico-philosofique sur l'aliénation mentale ou la manie, publicado em Paris, em 1801, que se gerou uma nova cultura médica para investigar o fenômeno da loucura. Dizia Pinel(4;:107-108):

Os loucos com quem mais trabalho costumo conter nos hospitais, aqueles que mais se distinguem por uma atividade tumultuosa, e os mais sujeitos às repentinas explosões de furor maníaco [...] O grande segredo de dominá-los em certas circunstâncias imprevistas, sem dar golpes nem recebê-los, é fazer com que venham muito subservientes, para inspirá-los uma espécie de medo por um aparelho que Ihe cause respeito [...] Então se intima, em poucas palavras e com um tom imperioso, que se rendam e obedeçam [...] um o pega do braço, outro de um músculo ou de uma perna e assim os demais. Com sorte, levam-nos e os metem na sua jaula, frustrando todos seus esforços, e o que era o presságio de uma cena trágica, termina de modo regular $[\ldots]$

Essa visão sobre a loucura coincidiu com o nascimento da psiquiatria como ciência médica. Com ela, nasce a concepção de loucura como desvio orgânico, sendo necessária sua correção em ambientes organizados estruturalmente e isolados de todo a convivência nociva com o meio social. Através de um tratamento baseado na autoridade, no isolamento e na subserviência, foi-se desenvolvendo todo um aparelho imaginário sobre a loucura como sentido de doença, de desvio, de erro e de periculosidade social. O hospital psiquiátrico não é só mais uma instituição de tratamento da loucura, mas também um recurso que abrange medidas protetoras da sociedade, impedindo-a de conviver com a diferença ${ }^{(5-6)}$.

Essa "verdade absoluta" cultivada pela medicina sobreviveu durante mais de 200 anos. No entanto, nos últimos anos, vivenciamos mudanças expressivas na construção do conhecimento sobre a loucura. Com o movimento da Reforma Psiquiátrica, iniciado no final da década de 1970 em diversos países do mundo, inclusive no Brasil, tem-se conseguido 
importantes avanços para a reversão de um modelo médico-centrado e calcado numa relação de subordinação do doente ao médico. Isso porque a loucura não se restringe mais a apenas uma dimensão biológica da vida, mas também à compreensão ampliada dos diversos processos de viver, levando-se em conta as relações interpessoais, as condições sociais, o contexto político, jurídico e cultural ${ }^{(6-7)}$.

Com essas mudanças, testemunham-se transformações no contexto dos serviços de saúde mental. Os recursos terapêuticos são reestruturados, em substituição ao hospital psiquiátrico, para possibilitarem o nascimento de serviços comunitários, que incorporam o suporte familiar, os laços afetivos, enfim, todo o território do sujeito no contexto do tratamento. É nesse bojo que surgem os Centros de Atenção Psicossocial (CAPS), destinados ao acolhimento das diferentes demandas e dimensões do sujeito que está vivenciando uma situação de sofrimento mental.

Essa reestruturação traz à tona uma nova concepção de loucura e um novo modelo de atenção em saúde mental, construídos a partir do olhar da inclusão e da perspectiva de cuidado a indivíduos que padecem psiquicamente. Assim, a loucura se complexifica, aparece como força ativa, como potencialidade de transformação, como produção de novos registros de tempo e de espaço ${ }^{(8)}$. Não pretendemos definir o que seria loucura, mas demonstrar que esse conceito é ampliado e que depende de múltiplos fatores, sem cairmos numa polaridade que não dá suas reais dimensões existenciais ${ }^{(9)}$. Nosso entendimento de loucura é como fenômeno com o qual podemos e devemos conviver, do qual devemos nos aproximar para descobrir o significado de sua existência.

Apesar dos avanços conquistados com a transformação do cuidado em saúde mental, aquele imaginário excludente sobrevive até hoje. A grande maioria das pessoas vê no manicômio uma saída para as manifestações muitas vezes exageradas da loucura. Isso tudo fruto da inclinação do preconceito por uma sociedade injusta e da redução do próprio conceito de loucura, a qual ainda é sentida como desvio social.

É nesse contexto que o atual artigo se insere. Tem por objetivo avaliar qualitativamente a relação de alguns atores sociais com a loucura a partir das experiências produzidas em um Centro de Atenção Psicossocial no contexto brasileiro. Procuramos apontar lacunas, potencialidades e limitações compartilhadas pelos grupos de interesse que fazem a saúde mental no cotidiano do serviço (usuários, familiares e profissionais).

\section{REFERENCIAL TEÓRICO-FILOSÓFICO}

Trata-se de um recorte de um estudo de avaliação qualitativa de Centros de Atenção Psicossocial que utilizou, como referencial teórico-filosófico, a Avaliação de Quarta Geração ${ }^{(10)}$. A proposta de realizar uma avaliação de serviço qualitativa vem da preocupação em apreender a sua dinâmica, a forma como os atores interagem e os sentidos que são construídos pelos mesmos em relação à sua prática. Junto com isso, uma avaliação que pudesse ser também um dispositivo, possibilitando, através do estabelecimento de um processo participativo, que grupos de interesse ampliem a possibilidade de intervirem sobre a realidade do serviço, que possam ser sujeitos em um processo que, em metodologias tradicionais, estão excluídos.

Os autores propõem, como alternativa às avaliações tradicionais, uma avaliação responsiva, baseada em um referencial construtivista. O termo responsiva é usado para designar uma diferente forma de focalizar a avaliação em relação aos seus parâmetros e limites: nos modelos tradicionais os parâmetros e limites são definidos a priori. A avaliação responsiva determina parâmetros e limites através de um processo interativo e de negociação que envolve grupos de interesse e que consome uma considerável porção de tempo e de recursos disponíveis. É por esta razão que o projeto de uma avaliação responsiva é chamado de emergente. O termo construtivista é usado para designar a metodologia empregada para realizar a avaliação e tem as suas raízes em um paradigma de pesquisa que é alternativo ao paradigma científico, e também é conhecido por outros nomes (interpretativo, hermenêutico). Um modo responsivo de focar e um modo construtivista de fazer.

A avaliação responsiva também tem seus organizadores de avanço: as reivindicações, preocupações e questões que serão identificadas por grupos de interesse (stakeholders), isto é, pessoas que serão potencialmente vítimas ou beneficiários da avaliação.

Podem existir três classes de stakeholders. A primeira seriam os agentes, que são todas pessoas envolvidas em produzir, usar e implementar o serviço. A segunda seriam os beneficiários, ou seja, todas as pessoas que se beneficiam de alguma forma com o uso do serviço. Já a terceira seriam as vítimas, isto é, as pessoas que são afetadas negativamente pelo uso do objeto avaliado, como: grupos excluídos do seu uso, grupos que sofreram efeitos negativos no seu uso, pessoas politicamente em desvantagem, sem poder, influência ou prestígio, pessoas que perderam oportunidades que não foram exploradas porque os recursos necessários estão alocados para darem suporte ao objeto da avaliação ${ }^{(10)}$.

Neste estudo, identificamos três grupos de interesse potenciais, protagonistas do cotidiano do serviço de saúde mental: usuários, trabalhadores e famílias. Entendemos que a mudança de paradigma preconizada na assistência em saúde mental exige a invenção de formas de pensar e fazer que não estão dadas, além da participação de pessoas diretamente envolvidas com esse processo, de forma que a inserção de diferentes atores responda à complexidade do 'novo' objeto construído e das práticas a eles direcionadas.

\section{O dispositivo metodológico}

Como dispositivo metodológico do processo de avaliação qualitativa, utilizamos o Círculo Hermenêutico-Dialético(10), em sua versão adaptada(11). Ele é utilizado na Avaliação de Quarta Geração como um caminho para alcançar o caráter construtivista e participativo. É hermenêutico porque tem caráter interpretativo e dialético porque implica em comparação e contraste de diferentes pontos de vista, objetivando um alto nível de síntese.

A seguir, ilustramos o dispositivo metodológico utilizado, bem como uma breve explicação de seu funcionamento: 


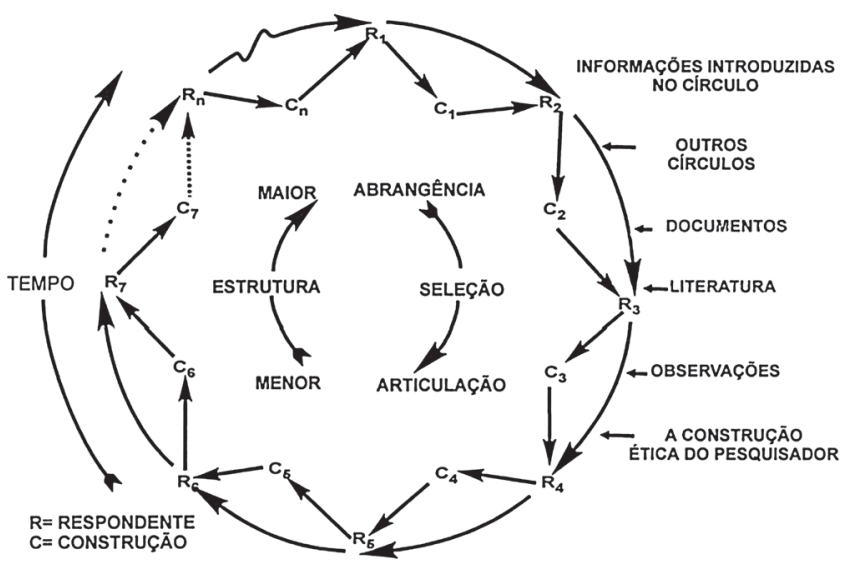

Figura 1 - Círculo Hermenêutico Dialético ${ }^{(10)}$

Como primeiro passo, um respondente inicial (R1) de cada grupo de interesse é selecionado pelo pesquisador, em função de sua posição estratégica em relação ao objeto da avaliação. É realizada uma entrevista aberta para determinar uma construção inicial em relação ao que será investigado ou avaliado - o foco da investigação. Pede-se que o respondente descreva o foco como ele ou ela o constrói, que o comente e descreva em termos pessoais. Em avaliações, estes comentários incluem observações sobre as reivindicações, problemas e questões, e sobre aspectos positivos e negativos do serviço. Ao final da entrevista, pode ser solicitado ao respondente que indique outro respondente (R2), que identifica como tendo construções diferentes das suas.

Os temas centrais, conceitos, idéias, valores, problemas e questões propostas por R1 são analisadas pelo pesquisador, em uma formulação inicial da sua construção, designada C1. Deste modo, a análise dos dados segue de perto a coleta de dados. Caso as questões sejam de grande importância e politicamente sensíveis, será útil checar a análise completa com R1.

De posse das informações finais de R1, R2 é entrevistado, e o círculo recomeça. O processo é repetido através da adição de novos informantes até que a informação recebida torne-se suficientemente redundante, ou quando duas ou mais construções permanecerem em conflito de alguma forma (tipicamente porque os valores que apóiam as diferentes construções estão em conflito). As informações disponíveis aos participantes do círculo não precisam ser limitadas àquelas que eles e o pesquisador trazem. É possível introduzir outras demandas que a oportunidade e a necessidade originam, tais como construções que emergem de outros grupos de interesse, dados de observação, documentos, literatura relevante e a construção ética do pesquisador.

\section{PROCEDIMENTOS METODOLÓGICOS}

O estudo foi desenvolvido junto a um Centro de Atenção Psicossocial, localizado numa cidade da região sul do Brasil. A coleta de dados baseou-se na utilização de entrevistas semiestruturadas, conduzidas de acordo com as orientações metodológicas do Círculo Hermenêutico-Dialético. Ela ocorreu nos meses de novembro e dezembro de 2006. Cada entrevista foi realizada individualmente e gravada, sendo transcritas na íntegra.

Os grupos de interesse selecionados para o estudo foram usuários, familiares e trabalhadores do serviço estudado, por entender que se caracterizam como os principais protagonistas das ações de saúde mental. Participaram das entrevistas dez profissionais, onze usuários e onze familiares. Todos assinaram o Termo de Consentimento Livre e Esclarecido, em cumprimento dos princípios éticos de anonimato dos sujeitos. Para isso, os trabalhadores foram identificados com a letra " $E$ ", os familiares, com a letra " $F$ " e os usuários com a letra " $U$ ", seguidos da ordem na entrevista (E1, U3, F7, e assim por diante).

O estudo foi aprovado pelo Comitê de Ética em Pesquisa da Faculdade de Medicina da Universidade Federal de Pelotas, ofício $n^{\circ}$ 074/2005. Foi também solicitada a autorização da Coordenadora de Saúde Mental do município e da Coordenadora do CAPS para o início da investigação, informando os objetivos e os princípios éticos do estudo.

A análise dos dados foi realizada concomitantemente à coleta, em que foi possível identificar os eixos temáticos para posterior discussão na negociação com os grupos de interesse. Após essa etapa, procedeu-se à organização do material empírico em unidades temáticas centrais, sendo estabelecidos marcadores de avaliação, ou seja, categorias oriundas da análise e reanálise desse material. Neste artigo discutiremos os resultados do marcador "relação da sociedade com o fenômeno da loucura".

\section{RESULTADOS E DISCUSSÃO}

O CAPS estudado iniciou suas atividades em 2004, dividindo o espaço físico do prédio alugado pela Prefeitura com o Ambulatório de Saúde Mental. O serviço tem uma demanda diária média de 90 pessoas, estando, no momento da coleta, com 180 usuários cadastrados.

O acesso ao serviço ocorre pelo ambulatório de saúde mental, sendo agendada uma entrevista inicial com um dos técnicos do CAPS conforme a escala de entrevista inicial. É uma entrevista para admissão do usuário, realizada por meio de anamnese, sendo definida pela equipe como acolhimento. Diariamente, são realizadas três avaliações, totalizando quinze no período de uma semana. Os encaminhamentos são feitos pelos psiquiatras do ambulatório de saúde mental.

No serviço são desenvolvidos atendimentos individuais, ainda não sistematizados que ocorrem aleatoriamente; atividades grupais como grupos operativos, psicoterapias, oficinas; atividades direcionadas para familiares, como reunião de família. O projeto terapêutico individual (PTI) ainda não foi implementado, apesar de existir um espaço específico para o mesmo na ficha de avaliação inicial.

No decorrer do processo avaliativo, com aplicação das entrevistas aos grupos de interesse, foram emergindo questões sobre o preconceito e o estigma da loucura. Ficou evidente que ainda se manifestam diferentes formas de exclusão, não 
apenas por parte da sociedade em geral, mas também por parte dos próprios profissionais do serviço.

Um dos fatores atribuídos para o fortalecimento desse preconceito parece ser o desconhecimento da comunidade sobre o trabalho que é realizado pelo CAPS, como demonstrado a seguir:

[...] está faltando é a comunidade se envolver um pouco mais com os serviços que a gente tem [...] conhecer [...] o que a gente faz aqui, o que a gente oferece [...] E5

Aí fora o pessoal não entende a gente, acha que a gente é vagabundo [...] aquele lá é um louco, não precisa falar, aquele lá é louco [...] U10

[...] isso aí é lugar de louco, então como a gente não conhece, a gente se engana muito [...] F4

A localidade onde vivemos representa apenas um dos muitos recortes de territórios que habitamos. O território pode ser considerado como uma determinada área geográfica, espacial, muito embora essa concepção de território seja restrita, uma vez que, nesse espaço, existem pessoas, instituições e trocas sociais. No campo da saúde, quando pensamos que a atenção à saúde deve ir ao encontro das pessoas, é necessário desenvolver o conceito que temos sobre o território, incluindo, no planejamento, a localização temporal, a disposição geográfica, além de fazer interfaces com os outros serviços da sociedade, de modo a organizar o atendimento para atender as demandas das pessoas ${ }^{(12)}$.

Nesse sentido, o território é, sim, um espaço geográfico, porém um espaço de trocas e singularizado por natureza. Possui seus limites temporais, políticos, administrativos e culturais, muitas vezes imprecisos, mas relativamente homogêneos, com certa identidade social, construída pela história. Um território contempla uma característica espacial ou demográfica específica, mas, mais do que isso, é um espaço portador de poder - nele se exercita e se constrói toda a rede de atuações do Estado, dos serviços e dos cidadãos que pertencem a ele. Reconhecer que é no território que ocorrem as disputas hegemônicas é um passo importante para avaliar a inserção dos serviços, das ações e das pessoas ${ }^{(13)}$.

Em saúde mental, quando falamos em território, estamos falando em articular serviços com diferentes finalidades, para ajudar na construção de territórios existenciais que possibilitem reinventar a vida em todos os seus aspectos do cotidiano, um cotidiano no qual a loucura foi privada de conviver. É desejável que as atividades funcionem como catalisadoras de novos territórios existenciais, nos quais os usuários possam reconquistar espaços perdidos e conquistar novos espaços, no decorrer de sua vida(14).

A atuação do CAPS tem o território como cenário fundamental para a reprodução e produção de novas trocas simbólicas e perspectivas existenciais para o louco, a loucura e suas relações sociais. Isso porque, por muito tempo a sociedade valorizou as instituições especializadas em excluir, oprimir e estigmatizar como o modo de tratamento e o resgate dos valores sobre a convivência com a loucura devem ocorrer por trocas mais subjetivas da experiência humana e pelo estímulo e inclusão de novas parcerias setoriais, Nesse sentido, entendemos que o CAPS possui um protagonismo no estabelecimento de uma rede de conversações entre esse território e a sociedade, um cenário capaz de ressituar o sujeito e a própria essência do processo de reforma do cuidado psiquiátrico.

Os depoimentos dos grupos de interesse vêm apontando a necessidade de investir mais na presença do CAPS no território onde se situa. F4 e U10, por exemplo, têm posicionamentos semelhantes sobre a finalidade da existência do CAPS. Eles dizem que é um "lugar para loucos", o que, entendemos, seja resquício de um discurso mais próximo de uma tendência excludente e perigosa da loucura, que estamos tentando superar. Mesmo assim, os próprios sujeitos manifestam que, ao conhecer realmente como funciona o serviço, ou seja, convivendo com ele, é possível desconstruir essa concepção.

No entanto, é interessante o depoimento de E5, em que parece que o movimento deva ocorrer de "fora pra dentro", no momento em que é direcionado para a comunidade o envolvimento maior com a dinâmica do serviço. Dessa forma, isso se torna um indicador de avaliação do processo de trabalho do serviço importante, especialmente quando falamos de um contexto de reforma que tem o território como cenário fundamental de sua prática. Fazer com que a comunidade venha ao CAPS (e não o contrário) pode estimular o seu isolamento, além de desenvolver uma compreensão social equivocada de que ele é um serviço responsável por trabalhar com demandas altamente especializadas, fora dos espaços de circulação da vida cotidiana.

A reforma psiquiátrica nasceu como movimento contestador, mas portando contradições importantes em seu interior, que muitas vezes favorecem o encolhimento do serviço sobre si mesmo e dificultam a sua expansão para o território. Uma dessas contradições se inicia na própria compreensão dos profissionais sobre o processo saúde/doença mental, muito relacionada à semelhança entre a normalidade como condição de ajustamento social e à patologia como condição de desajustamento. Nesse sentido, muitos trabalhadores se limitam- a abordar a sua prática com o lado "menos saudável" da loucura, encerrando na sua institucionalização. Em outras palavras, a "inclusão na comunidade" - defendida como premissa ideológica de reabilitação psicossocial - parece se transformar em "inclusão no serviço", fato esse que esvazia o serviço e estimula a cronificação do louco e da loucura(15).

Vale ressaltar que perceber o papel de libertar sujeitos em meio a um território vasto e que, durante séculos, foi controlado pelo poder médico-hegemônico, é complexo. No entanto, parece mais simples fazer com que o território se adapte às regras e rotinas dos serviços de saúde do que o contrário. Isso nos aponta para uma tendência de que ainda há, no discurso do profissional de saúde mental, vieses fortemente tradicionais, de origem manicomial, que, no contexto da reforma psiquiátrica, precisam ser suplantados.

Portanto, talvez resida aí o maior nó da reforma, que é transformar o olhar que construímos durante séculos sobre a loucura. Trata-se não apenas de reestruturar serviços de 
saúde, mas de ressignificar a dimensão sociocultural da reforma. Deve-se investir na desmistificação do aparelho psiquiátrico e da ideologia psiquiátrica do senso comum, com o objetivo de restabelecer as trocas simbólicas entre loucura, sujeito, comunidade e sociedade ${ }^{(16)}$.

Defendemos, portanto, a necessidade de se exteriorizar o trabalho que é desenvolvido no CAPS, utilizando recursos da própria comunidade para cuidar dos indivíduos que sofrem psiquicamente. O CAPS saindo de dentro de si mesmo e se permitindo transitar nos espaços comunitários, pode fortalecer a desmistificação do conceito de louco e de loucura, mostrando que é possível estar fora dos muros institucionais. O serviço deve instigar a sociedade a conhecê-lo, bem como conhecer os anseios, as expectativas, os recursos e as demandas dessa sociedade.

No entanto, apesar de ainda muito circunscrito sobre si mesmo, o próprio serviço vem lutando para exercer seu papel de desmistificador do ideário tradicional sobre a loucura, proporcionando a geração de novos sentidos sobre ela. Segundo os depoimentos a seguir, é possível notar que o CAPS tem ajudado os usuários a enfrentarem o preconceito, proporcionando apoio e acolhimento:

[...] quando você chega aqui eles não olham se você está bem vestido [...] se você está a pé ou de bicicleta ou se você está de carro, eles te recebem da mesma maneira [...] as pessoas vão ver isso com outros olhos, não com aqueles olhos e vão dizer assim 'lá só tem louco'. Eles vão dizer 'lá tem pessoas capazes' [...] 'competentes' [...] U5

[...] porque eles não têm preconceito de paciente nenhum [...] eles atendem todo mundo igual [...] o tratamento é igual [...] F5

[...] vai perdendo o preconceito [...] vai vendo como que é tratado aquele paciente [...] vai passar a dar mais amor [...] vai aprender a se relacionar muito mais com a família [...] F4

A psiquiatria, durante séculos, sustentou-se na premissa de que a instituição psiquiátrica (o manicômio), sob a aparência do modelo médico-hegemônico, destina-se a administrar o aspecto social da doença mental, e não a doença propriamente dita. Em medicina, estamos lidando com corpos doentes, que exigem certa intervenção técnica que o restabeleça. Mas no hospital psiquiátrico, é necessário administrar um doente que não é mais aceito no mundo e que ultrapassou todos os limites da norma fixada por ele, o que mostra o poder do manicômio não como terapêutico, mas como instituição opressiva e mortificante ${ }^{(17)}$.

A ciência psiquiátrica moderna trouxe ao mundo uma nova explicação sobre a doença, a saúde e a natureza, bem como suas interlocuções. Se pudermos examinar melhor, a doença mental, como condição comum, tem significados distintos conforme o sistema que a administra e regulamenta. Esse entendimento sobre a doença mental não está relacionado inicialmente a sua "evolução" como conceito, mas sim com o tipo de relação que ela estabelece com o médico, e, por consequência, com a sociedade que ele representa. Uma relação aristocrática, em que o poder contratual do paciente é oposto ao poder contratual do médico, em que a reciprocidade só acontece se houver concordância do técnico; uma relação "mutualística", em que há redução drástica do poder técnico e um aumento do poder arbitrário, desenvolvendo um novo mecanismo de tutela; e uma relação institucional, pois essa relação de poder desigual (médico-doente) só acontece porque há um hospital psiquiátrico que a reproduz e alimenta(18).

Os sentidos da loucura - tanto na sua vivência como na ontologia da existência e na "não-ontologia", aprisionados por uma ciência reducionista e corporificados num conjunto de manifestações de abandono, exclusão e classificação, têm mostrado o quanto o homem ainda "desentende" o sentido de sua própria vida e de seus fenômenos. No contexto da reforma psiquiátrica, no entanto, a tendência de fragmentação e coisificação do outro vem sendo superada pela iniciativa de reconexão entre o sujeito, suas relações, sua cultura, seus fenômenos e seu conhecimento de mundo. Isso porque é importante, sim, reformar serviços, mas também reformar pessoas, evitando engessamento, normalizações, relações de tutela e de docilização. Incentivar práticas de libertação e problematização da realidade tensionam não apenas o próprio conceito de loucura, mas também aquilo que tememos e compreendemos dela.

O CAPS, como serviço estratégico da reforma psiquiátrica brasileira, vem sendo percebido como um espaço de compartilhamento de vivências e de diminuição dos sentimentos de isolamento social. F4 e F5, por exemplo, ao avaliarem as experiências do serviço, mencionam que há dois indicadores importantes que devem ser considerados no contexto da reforma psiquiátrica: o primeiro é a iniciativa dos profissionais do serviço em valorizar a existência do indivíduo, e, o segundo, o estímulo à interação com suas famílias.

Avaliamos que essas transformações, ou seja, o fato de famílias e usuários serem valorizados pelo serviço pode ser entendido como a primeira experiência de superação de modalidades docilizadoras e castradoras da loucura, como aquelas restritas ao modelo proposto pelo manicômio. Nos depoimentos de familiares e usuários, fica evidente que o serviço vem incorporando a inclusão social como um de seus instrumentos do processo de trabalho, principalmente por acreditar mais na potencialidade do que na limitação do louco. Um serviço que caminha para a compreensão ampliada das diferentes histórias de vida, que vem possibilitando o reposicionamento de relações entre atores e instituições. E, desse modo, confrontando os modos estigmatizadores da loucura que tem limitado a vida social da pessoa com transtorno psíquico e sua família.

\section{CONSIDERAÇÕES FINAIS}

Avaliamos que o território constitui-se uma premissa importante para as ações de saúde mental propostas pelo CAPS. Em meio a ele, contradições residem entre o que seria fruto de uma postura da libertação - o externo, a desmistificação 
da loucura, o trabalho com a comunidade - e o que seria tendência de institucionalização - o trabalho interno, o fechamento do serviço e o pouco espaço aberto para as práticas comunitárias.

Os depoimentos perseguem a desinstitucionalização como paradigma da atenção em saúde mental, evidenciando a necessidade de combater os vícios carregados de condutas cristalizadas e excludentes, típicas do modelo manicomial. No entanto, o modelo manicomial ainda convive com aquele modelo que nasceu para superá-lo, ou seja, um modelo centrado em práticas ampliadas e inovadoras, voltadas para a libertação e produção de novos sentidos e novas pessoas.

O estudo em questão apresentou parte do processo avaliativo das práticas em saúde mental, apontando limitações e potencialidades do serviço estudado e das práticas no seu interior. Além de ser uma proposta metodológica viável para a avaliação de serviços, esperamos que ele possa problematizar o cotidiano dos mesmos, abrindo caminhos para recompreender a loucura, o louco e suas relações.

Confrontar o preconceito exige uma ação compromissada para romper barreiras, admitindo espaços de liberdade, valorização do sujeito cidadão e autônomo, ou seja, o desafio que se coloca é buscar novas relações, novas práticas que repensem as ações intervencionistas e limitantes da nossa convivência com a loucura e o louco.

Assim, o CAPS é avaliado como um serviço potente, sinalizador na promoção de mudanças nos campos teórico-conceitual e técnico-assistencial, na qual singularidade e pluralidade são destaques na superação do conceito de cura, de classificação, de desvio, de incapacidade e de periculosidade da loucura.

Romper com preconceitos que aprisionam sujeitos e histórias de vida torna-se um desafio, e requer o reconhecimento da pessoa em sofrimento mental como tal, valorizando-a como alguém que pode e faz. Um sujeito social, capaz de estabelecer trocas, produzir conhecimentos e laços de afeto e solidariedade.

Hoje, torna-se necessário valorizar uma prática que tenha como objetivo proporcionar ao louco todas as possibilidades para exercer sua subjetividade, aumentando sua capacidade de escolha, de falar sobre si, sua história, cultura, vida cotidiana e seu trabalho, ou seja, é um sujeito que estabelece relações na sociedade e participa dela, sendo influenciado por ela e influenciando-a.

\section{REFERÊNCIAS}

1. Foucault M. O nascimento da clínica. 6. ed. Rio de Janeiro: Forense Universitária; 2004.

2. Rodrigues AC, Costa CAR, Silva MEAS, Silva EP. Psicanálise, saber e conhecimento. Rev Dep Psicol UFF 2005;17(2):99-108

3. Descartes R. Discurso do método [monografia na internet] São Paulo; 2000 [acesso em 09 mar 2009]. Disponível em: < http://www.dominiopublico.gov.br/pesquisa/ detalheobraform.do?select_action $=\&$ co_obra $=2274>$.

4. Pinel P. Tratado médico-filosófico de la enajenación mental o manía. Madrid: Ediciones Nuevas; 1801

5. Foucault M. História da loucura. 8. ed. São Paulo: Perspectiva; 2003.

6. Alverga $A R$, Dimenstein M. A loucura interrompida nas malhas da subjetividade. In: Amarante P, organizador. Archivos de saúde mental e atenção psicossocial. Rio de Janeiro: Nau; 2005. p. 45-66.

7. Hirdes A. A reforma psiquiátrica no Brasil: uma (re)visão. Ciênc Saúde Coletiva 2009;14(1):297-305.

8. Carvalho AMT, Amarante P. Forças, diferença e loucura: pensando para além do princípio da clínica. In: Amarante P, organizador. Ensaios: subjetividade, saúde mental, sociedade. Rio de Janeiro: Fiocruz; 2000. p. 41-52.

9. Schrank G, Olschowsky A. O Centro de Atenção Psicossocial e as estratégias para inserção da família. Rev Esc Enferm USP 2008;42(1):127-34.

10. Guba E, Lincoln Y. Fourth Generation Evaluation. Newbury Park: Sage Publications; 1989.
11. Wetzel C. Avaliação de serviço em saúde mental: a construção de um processo participativo. São Paulo. Tese [Doutorado em Enfermagem]- Universidade de São Paulo; 2005.

12. Ministério da Saúde (Brasil). Saúde mental no SUS: os Centros de Atenção Psicossocial. Brasília: Ministério da Saúde; 2004.

13. Gondim GMM, Monken M, Rojas LI, Barcellos C, Peiter P, Navarro $M$, et al. O território da saúde: a organização do sistema de saúde e a territorialização. In: Miranda AC, Barcellos C, Moreira JC, Monken M, organizadores. Território, saúde e ambiente. Rio de Janeiro: Fiocruz; 2008. p.237-55.

14. Pinho LB, Bañon Hernández AM, Kantorski LP. Serviços substitutivos de saúde mental e inclusão no território: contradições e potencialidades. Ciênc Cuid Saúde 2010;9(1):28-35.

15. Pinho LB, Kantorski LP, Bañon Hernández AM. A concepção de clientela: análise do discurso da benevolência no contexto da reforma psiquiátrica brasileira. Rev Bras Enferm 2010;63(3):377-84.

16. Amarante P. A clínica e a reforma psiquiátrica. In: Amarante $\mathrm{P}$, organizador. Archivos de saúde mental e atenção psicossocial. Rio de Janeiro: Nau; 2003. p.45-65.

17. Goffman E. Manicômios, prisões e conventos. 3. ed. São Paulo: Perspectiva; 1990.

18. Basaglia F. Escritos selecionados em saúde mental e reforma psiquiátrica. Rio de Janeiro: Garamond; 2005. 